
Revue canadienne de de microbiologie

\title{
Isolation of lactic acid bacteria from swine milk and characterization of potential probiotic strains with antagonistic effects against swine-associated gastrointestinal pathogens
}

\begin{tabular}{|c|c|}
\hline Journal: & Canadian Journal of Microbiology \\
\hline Manuscript ID & cjm-2015-0811.R1 \\
\hline Manuscript Type: & Article \\
\hline Date Submitted by the Author: & 03-Feb-2016 \\
\hline Complete List of Authors: & $\begin{array}{l}\text { Quilodrán Vega, Sandra Rayén; Universidad de Concepcion, Facultad } \\
\text { Ciencias Veterinarias } \\
\text { Villena, Julio; Centro de Referencia para Lactobacilos. CERELA-CONICET } \\
\text { Valdebenito Chávez, José Osvaldo ; Laboratory of Bacterial Pathogenicity, } \\
\text { Microbiology Department, Faculty of Biological Sciences, University of } \\
\text { Concepcion, Concepcion, Chile. } \\
\text { Salas Jara, María José ; Laboratory of Bacterial Pathogenicity, Microbiology } \\
\text { Department, Faculty of Biological Sciences, University of Concepcion, } \\
\text { Concepcion, Chile } \\
\text { Parra Sepulveda, Cristian Andres; Laboratory of Bacterial Pathogenicity, } \\
\text { Microbiology Department, Faculty of Biological Sciences, University of } \\
\text { Concepcion, Concepcion, Chile. } \\
\text { Ruiz, Alvaro ; Laboratory of Bacterial Pathogenicity, Microbiology } \\
\text { Department, Faculty of Biological Sciences, University of Concepcion, } \\
\text { Concepcion, Chile. } \\
\text { Kitazawa, Haruki; Food Immunology Group, Laboratory of Animal Products } \\
\text { Chemistry Department of Science of Food Function and Health, Graduate } \\
\text { School of Agricultural Science- Tohoku University } \\
\text { Cancino, Apolinaria Garcia; University of Concepcion, }\end{array}$ \\
\hline Keyword: & probiotics, swine milk, Lactobacillus curvatus TUCO-5E, intestinal infection \\
\hline
\end{tabular}

\section{SCHOLARONE"}


3

4

\section{Isolation of lactic acid bacteria from swine milk and characterization of potential probiotic} strains with antagonistic effects against swine-associated gastrointestinal pathogens

Sandra Rayén Quilodrán-Vega ${ }^{1}$, Julio Villena ${ }^{2,3}$, José Osvaldo Valdebenito Chávez ${ }^{1}$, María José Salas Jara ${ }^{4}$, Cristian Andres Parra Sepulveda ${ }^{4}$, Alvaro Ruiz ${ }^{1}$, Haruki Kitazawa ${ }^{5,6}$, and Apolinaria García Cancino ${ }^{2,4 *}$

${ }^{1}$ Laboratory of Food Microbiology, Faculty of Veterinary Sciences, University of Concepcion, Chillan, Chile.

${ }^{2}$ Immunobiotics Research Group

${ }^{3}$ Laboratory of Immunobiotechnology, Reference Centre for Lactobacilli (CERELA-CONICET). Tucuman, Argentina.

${ }^{4}$ Laboratory of Bacterial Pathogenicity, Microbiology Department, Faculty of Biological Sciences, University of Concepcion, Concepcion, Chile.

${ }^{5}$ Food and Feed Immunology Group, Laboratory of Animal Products Chemistry, Graduate School of Agricultural Science, Tohoku University, Sendai, Japan.

${ }^{6}$ Livestock Immunology Unit, International Education and Research Center for Food Agricultural Immunology (CFAI), Graduate School of Agricultural Science, Tohoku University, Sendai, Japan.

* Corresponding author. Mailing address for Apolinaria Gacía: Laboratory of Bacterial Pathogenicity, Microbiology Department, Faculty of Biological Sciences, University of Concepcion, Concepcion, Chile. E-mail: apgarcia@udec.cl 
Abstract

Probiotics are usually isolated from the gastrointestinal tract of humans and animals. The search of probiotics in human milk is a recent field of research, as the existence of the human milk microbiome was discovered only about a decade ago. To our knowledge, no reports regarding the potential probiotic effect of bacteria from swine milk were published. In this work, we isolated several lactic acid bacteria from swine milk and evaluated them for them potential as probiotics. Among the isolated strains, Lactobacillus curvatus TUCO-5E showed antagonistic effects against swine-associated gastrointestinal pathogens. TUCO-5E was able to reduce the growth of enterotoxigenic and enterohemorragic E. coli strains as well as pathogenic Salmonella. In vitro exclusion and displacement assays in intestinal epithelial cells showed a remarkable antagonistic effect for L. curvatus TUCO-5E against Salmonella TUCO-I7 and S. enterica ATCC 13096. Moreover, by using a mice model of Salmonella infection we were able to demonstrated that $L$. curvatus TUCO-5E preventive administration during 5 consecutive days was capable of decreasing the number of $S$. typhimurium in the liver and spleen of treated mice when compared to controls, and avoided dissemination of the pathogen to the blood stream. Then, we demonstrated here that swine milk is an interesting source for finding beneficial bacteria. In addition, the results of this work suggest that L. curvatus TUCO-5E is a good candidate for in vivo studying the protective effect of probiotics against intestinal infection and damage induced by Salmonella infection in the porcine host.

Running title: Isolation of probiotic bacteria from swine milk

Keywords: Probiotics, pigs, swine milk, intestinal infection, Salmonella, Lactobacillus curvatus TUCO-5E 
51

\section{Introduction}

Antibiotics have played a major role in the growth and development of the swine industry for more than 50 years. Their efficiency in increasing growth rate, improving feed utilization and reducing mortality from clinical disease is well documented (Cromwell 2002, Emborg et al. 2004). However, the excessive use of antibiotics as growth promoters in the pig industry results in the development of antibiotic resistant strains of human and animal pathogens (Emborg et al. 2004). Moreover, such antibiotics can be lethal to beneficial microorganisms in the gastrointestinal tract of human and animals and, they may also enter the food chain and accumulate in human body as undesirable chemical residues. Therefore, there is a need for development of alternative control methods to the antibiotics used in feed to protect the animals from diseases such as infectious diarrhea (Thacker 2013). One of the alternative methods is biological control using probiotics (Villena and Kitazawa 2014), that are defined as live microorganisms which, when administered in adequate amounts, confer a health benefit on the host (FAO/WHO).

Several studies have shown that probiotics can beneficially improve health status of pigs and reduce susceptibility to infections (Villena and Kitazawa 2014; Suda et al., 2014). In this regard, Qiao et al. (2004) conducted experiments to evaluate the effects of a complex Lactobacilli preparation on performance, resistance to E. coli infection and gut microbial flora of weaning pigs. The mix of four lactobacilli (L. gasseri, L. reuteri, L. acidophilus and L. fermentum) isolated from weaning pigs was able to reduce $E$. coli and anaerobe counts in the gut, and decrease diarrhoea. Herfel et al. (2013) examined the impact of a novel probiotic strain of Bifidobacterium longum AH1206 on the health, growth and development of neonatal pigs. Authors found that AH1206 supplementation modulated the inflammatory tone of the intestinal mucosa of suckling piglets. However, no differences were found between AH1206-treated and control piglets when comparing body weight gain, feed efficiency, and histological and physiological modifications in intestines. In addition, some studies have specifically evaluated the capacity of probiotics to improve the 
77

78

79

80

81

82

83

84

resistance of piglets against enterotoxigenic Escherichia coli (ETEC). It was shown that the probiotic strain L. plantarum CJLP243 may serve as a potential alternative to antibiotic supplementation to improve the growth and health performance of weaning pigs because of its capacity to reduce the severity of ETEC-induced diarrhea (2012). Li et al. (2012) also showed that pretreatment of piglets with L. rhamnosus ATCC7469 ameliorates F4 ${ }^{+}$ETEC-induced diarrhoea. More recently, it was proposed that Enterococcus faecium NCIMB 10415 exerts an immune modulatory effect by increasing the numbers of intraepithelial lymphocytes in weaned pigs and improves protection against Salmonella enterica serovar Typhimurium (Rieger et al. 2015). These results demonstrate that is possible to modulate piglets' gut microbiota and immunity and improve growth performance by using appropriate probiotics strains.

Probiotic strains have been usually isolated from the gastrointestinal tract of humans and animals. On the other hand, probiotics in human milk are a very recent field of research, as the existence of the human milk microbiome was discovered only about a decade ago (Martin et al., 2003; Latuga et al. 2014; Jost et al. 2015). Current research is focusing on bacterial diversity and the influence of the maternal environment as well as the mode of delivery on human milk microbiota, the pathways of bacterial transfer to milk ducts, possible benefits of specific bacterial strains for the treatment of mastitis in mothers, and disease prevention in children (for a review see Bergmann et al. 2014). Moreover, recent advances in the assessment of early host-microbe interactions suggest that early colonization of infant gut by milk bacteria may have an impact on later health (Bergmann et al. 2014). To our knowledge, no reports regarding the potential probiotic effect of swine milk bacteria were published. Then, the objective this work was the isolation of beneficial lactic acid bacteria (LAB) inhabiting swine milk, which can be used as potential probiotics against swine gastrointestinal bacterial pathogens.

\section{Materials and Methods}


104

Ten swine milk samples were collected aseptically by trained personnel in the rotahouse from Sucesión Salvador Yanine Abadi, Bulnes, Chile. The samples were transported to the Laboratory of Food Microbiology, Faculty of Veterinary Sciences, University of Concepcion (Chillan, Chile), in cold containers. For the isolation of LAB from swine milk, resistance to $\mathrm{pH} 3$ was used as a selection criterion. For this purpose, $100 \mu \mathrm{l}$ of each milk sample were placed in MRS broth and, incubated at $37{ }^{\circ} \mathrm{C}, 5 \% \mathrm{CO}_{2}$ for 12 hours. Then, $100 \mu$ of each tube they were transferred to MRS broth $\mathrm{pH} 3(\mathrm{HCl}, 5 \mathrm{~N})$ and incubated for 3 hours under the same conditions. After that period, the cultures were transferred to MRS agar to verify their viability. The grown colonies were subjected to Gram staining and catalase test. Colonies of Gram positive and catalase negative microorganisms resistant to $\mathrm{pH} 3$ were selected for subsequent studies.

\section{Identification of isolated strains}

The isolates confirmed as Gram-positive and catalase-negative bacilli were biochemically identified using the API test as described elsewhere. Bacteria were further identified using speciesspecific primers (Table 1). Genomic DNA extraction was performed using the ZR Fungal/Bacterial DNA Miniprep Kit commercial kit (Catalog D6005). In a first step, the samples were amplified using the primers Lac (forward: 5' ACA GAC TGA AAG TCT GAC GG and reverse: 5' GCG ATG CGA ATT TCT ATT ATT) and LbG (forward: 5' AGA AGA GGA CAG TGG AAC and reverse: 5, TTA CAA ACT CTC ATG GTG TG). A total volume of $25 \mu 1$ was used for amplifications $(12.5 \mu \mathrm{l}$ of Master Mix, $0.2 \mu \mathrm{l}$ of each primer and $5 \mathrm{ng}$ of total DNA from each strain). As a positive and negative controls genomic DNA from Lactobacillus GG and PCR mix without DNA were used respectively. Amplification consisted of an initial step of $94{ }^{\circ} \mathrm{C}$ for $60 \mathrm{~s}$, followed by 30 cycles of $98{ }^{\circ} \mathrm{C}$ for $60 \mathrm{~s}, 55$ for $40 \mathrm{~s}$ and, $72{ }^{\circ} \mathrm{C}$ for $40 \mathrm{~s}$. Positive strains for the 
129

130

131

132

133

134

135

136

137

138

139

140

141

142

143

144

145

146

147

148

149

150

151

152

153

154

genus Lactobacillus were subjected to PCR analysis using the species-specific primers as follow: 10 $\mu \mathrm{l}$ of DNA, $2.5 \mu \mathrm{l}$ of buffer (10X), $1.25 \mu \mathrm{l}$ of $\mathrm{MgCl}_{2}(50 \mathrm{mM}), 0.5 \mu \mathrm{lNTPs}(10 \mu \mathrm{M}), 1.25 \mu \mathrm{l}$ of each primer $(0.5 \mu \mathrm{M})$ and, $0.125 \mu \mathrm{T}$ Taq $(500 \mathrm{U})$, in a final volume of $25 \mu \mathrm{l}$. Salmonella Typhimurium DNA and Lactobacillus fermentum UCO-979C DNA were used as negative and positive controls respectively. Two bacterial strains TUCO-7A and TUCO-5E, showing potential probiotic properties, were further identified by 16s RNA sequencing.

\section{Gastrointestinal bacterial pathogens}

Several bacterial pathogens were used to evaluate the antagonistic effect of isolated LAB. Escherichia coli ATCC 25922 and Salmonella enterica ATCC 13076 were obtained from Oxoid. Salmonella sp. TUCO-I7 (isolated form intestines of infected pigs), enterotoxigenic E. coli TUCOI5 and enterohemorragic E. coli TUCO-I6 provided by the Faculty of Veterinary Sciences, University of Concepcion (Concepcion, Chile). Escherichia coli strains and Salmonella strains were grown in BHI broth.

\section{Antibiotic resistance and hemolysins and gelatinases detection}

To assess resistance to antibiotics, the selected strains were cultured in Müeller Hinton agar from a suspension of 0.5 Mc Farland. The sensidiscs of the following antibiotics were used: ciprofloxacin $(5 \mu \mathrm{g})$, vancomicin $(30 \mu \mathrm{g})$, amoxicilin $(25 \mu \mathrm{g})$, ampicilin $(10 \mu \mathrm{g})$, gentamicin $(10$ $\mu \mathrm{g})$, erythromycin $(15 \mu \mathrm{g})$ and doxycycline $(30 \mu \mathrm{g})$. Plates were cultured at $37^{\circ} \mathrm{C}$ during 48 hour.

The inhibition halo was measured in cm and the criterium of Vlkova' et al. (2006) and CLSI (2008) were used to determine resistance or susceptibility to antibiotics.

For hemolysins and gelatinases detection strains were cultured in Columbia blood agar or in gelatin at $35^{\circ} \mathrm{C}, 5 \% \mathrm{CO}_{2}$ during 48 hours, respectively. 
155

156

157

158

159

160

161

162

163

164

165

166

167

168

169

170

171

172

173

174

175

176

177

178

179

180

\section{Resistance to $\mathrm{NaCl}$ and Oxgall}

The selected strains were cultivated in MRS broth containing 3\%, $6.5 \%$ or $9 \% \mathrm{w} / \mathrm{v} \mathrm{NaCl}$ or in in MRS broth containing 0.3, 0.6, 2, 3 or $5 \% \mathrm{w} / \mathrm{v}$ Oxgall, as described by Cai et al. (1999). The tubes were incubated for 5 days at $37{ }^{\circ} \mathrm{C}, 5 \% \mathrm{CO}_{2}$ and the growth of the strains was observed. Then, $100 \mu l$ of each tube were streaked on MRS agar to test viability.

\section{Hydrophobicity evaluation}

As described by Gusils et al. (2002) strains were grown in MRS broth and centrifuged at 1500 rpm for $10 \mathrm{~min}$. The pellets were washed twice with buffer Butterfield (pH 7.2) and resuspended in $1.2 \mathrm{ml}$ of the same buffer. The absorbance was measured at $600 \mathrm{~nm}(0.4-0.6)$. A volume of $0.3 \mathrm{ml}$ of xilol was mixed with $1.2 \mathrm{ml}$ of the bacterial suspension in a vortex during $1.5 \mathrm{~min}$. After the separation of the phases $(20 \mathrm{~min})$ the aqueous phase was removed and the absorbance was measured again. The hydrophobicity percentage was calculated by the formula (Ai - Af) Ai x 100, being Ai and Af the initial and final absorbances respectively.

\section{Inhibition of bacterial pathogens}

Study of bacterial pathogens inhibition was performed according to Moore et al. (2013). A 10 $\mu 1$ loop of a two day culture on MRS agar of LAB strains were streaked on a line on MRS agar and incubated at $37{ }^{\circ} \mathrm{C}, 5 \% \mathrm{CO}_{2}$ for 24 hours. After this period, a $10 \mu \mathrm{l}$ loop of overnight cultures from the pathogens strains were streaked perpendicular to the LAB strains lines. The plates were incubated for $37{ }^{\circ} \mathrm{C}$ during 48 hours in aerobic conditions. The inhibition zones were measured in centimeters. 


\section{Exclusion and displacement assays}

The Caco-2 cell line were cultivated in complete Dulbecco's modified Eagle's minimal essential medium (DMEM) supplemented with heat-inactivated fetal bovine serum $(10 \% \mathrm{v} / \mathrm{v}), 2,5$ $\mu \mathrm{g} / \mathrm{ml}$ streptomycin/amphotericin, $2 \mathrm{mM}$ L-glutamine, $1 \%$ non-essential amino acids. The medium was replaced every two days. Cells were grown at $37^{\circ} \mathrm{C}, 5 \% \mathrm{CO}_{2}, 95 \%$ humidity in $\mathrm{T} 25$ flasks. After 6 days, cells were washed with PBS buffer and transferred into the culture medium without antibiotic solution. Cell were grown for another two days until $80 \%$ of confluence to be used for adhesion experiments.

Bacterial assays on Caco-2 cells were evaluated using 24-well plates. Suspensions of LAB and pathogens strains were prepared with DMEM medium.

For the exclusion assays, bacterial cells were washed twice with PBS. A volume of $200 \mu 1$ of LAB suspension $\left(1 \times 10^{8} \mathrm{ufc} / \mathrm{ml}\right)$ was added to each well and the plates were incubated at $35^{\circ} \mathrm{C}$ for $45 \mathrm{~min}$. After that period, a volume of $200 \mu \mathrm{l}$ of pathogen bacterial suspension $\left(1 \times 10^{8} \mathrm{ufc} / \mathrm{ml}\right)$ was added to each well. After 45 min of incubation, the monolayers were washed two times with PBS to eliminate unbound bacteria. Following the last wash, Caco-2 cell monolayers were covered with $200 \mu 1$ distilled water and mechanically agitated by vigorous pipetting.

For displacement assays, a volume of $200 \mu \mathrm{l}$ of pathogen bacterial suspension $\left(1 \times 10^{4} \mathrm{ufc} / \mathrm{ml}\right)$ was added to each well. The plates were incubated at the same conditions described above. Then, $200 \mu \mathrm{l}\left(1 \times 10^{8} \mathrm{ufc} / \mathrm{ml}\right)$ of LAB suspension was added to each well and incubated for $45 \mathrm{~min}$. The monolayers were washed two times and after the last wash, they were mechanically agitated by vigorous pipetting to detach bacteria and cells.

For both assays, the adherent bacteria were counted on Chromocult agar (Merck) (previously serial dilution) and incubated at $35^{\circ} \mathrm{C}$ for 24 hours.

\section{Animals, feeding procedures and infection}


Male 6-week-old Balb/c mice were obtained from CERELA and animal studies and protocols were approved by the CERELA Ethical Committee of Animal Care. Mice were housed in plastic cages at room temperature. Animals were housed individually during the experiments and the assays for each parameter studied were performed in 5-6 mice per group. L. curvatus TUCO-5E were administered to different groups of mice for 5 consecutive days at dose of $10^{7}, 10^{8}$ or $10^{9}$ cells/mouse/day in the drinking water. The treated groups and the untreated control group were fed a conventional balanced diet ad libitum. Treated and control mice were challenged with $50 \mu 1$ of $10^{7}$ cells/ mouse of S. typhimurium (20LD50) by oral administration. Mice were sacrificed on days 2 post-infection. The liver and spleen of mice in the different experimental groups were removed. Organs were homogenized in $0.1 \%$ peptone water, diluted appropriately and plated in MacConkey agar. Plates were incubated at $37^{\circ} \mathrm{C}$ for $48 \mathrm{~h}$. Results were expressed as the number $(\log )$ of $\mathrm{CFU} / \mathrm{g}$ of organ. Bacteremia was monitored by blood samples obtained by cardiac puncture which were plated on MacConkey agar. Results were expressed as the number (log) of CFU/ml of blood.

\title{
Statistical analysis
}

Experiments were performed in triplicate and results were expressed as mean \pm standard deviation (SD). After verification of the normal distribution of data, 2-way ANOVA was used. Tukey's test (for pairwise comparisons of the means) was used to test for differences be- tween the groups. Differences were considered significant at $\mathrm{p}<0.05$.

\section{Results}

\author{
Isolation and identification of bacterial strains
}


The aim of the present study was to isolate and identify potential probiotic LAB from swine milk. A total of 47 different bacterial colonies were isolated from 10 samples of swine milk. Among these, 10 strains showed the capacity to grow in MRS broth at $\mathrm{pH}$ 3. Preliminary studies evaluating the capacity of LAB strain to inhibit E. coli ATCC23922 allowed us to select two strains for further research: TUCO-7A and TUCO-5E. The two bacterial strains were Gram+ bacilli (Figure 1). API analysis and molecular biology studies allow us to determine that both strains belong to genus Lactobacillus (data not shown). Moreover, 16s RNA sequencing indicated that the strain TUCO-7A showed a 99.4\% of identity with Lactobacillus brevis ATCC14869 (GeneBank: M58810) while strain TUCO-5E showed a 99.7\% of identity with Lactobacillus curvatus ATCC25601 (GeneBank: M113777). Therefore, the strains were designated as Lactobacillus brevis TUCO-7A and Lactobacillus curvatus TUCO-5E.

\section{Antibiotic resistance and safety evaluation of selected strains}

An important requirement of probiotic strains is that they should not take genes that confer antibiotic resistance. Then, the antibiotic susceptibility of the two selected strains was determined using various antibiotic agents. The results showed that the strains were susceptible to amoxicillin, ampicillin, gentamicin, and erythromycin while both lactobacilli were resistant to vancomicin (Table 2). L. curvatus TUCO-5E was susceptible to ciprofloxacin while L. brevis TUCO-7A was resistant to that antibiotic. In addition, results showed that TUCO-7A strain was moderately susceptible to doxycycline (Table 2).

Absence of haemolytic activity is also considered as a safety prerequisite for the selection of a probiotic strain. None of the examined strains exhibited $\alpha$ or $\beta$-haemolytic activity when grown in Columbia human blood agar (Table 3). Additionally, the two lactobacilli were negative for the detection of gelatinase activity (Table 3 ). 
L. curvatus TUCO-5E and L. brevis TUCO-7A were tested for their ability to grow in presence of bile salts $(0.3,0.6,2,3$ and $5 \% \mathrm{w} / \mathrm{v})$ and $\mathrm{NaCl}(3,6.5$ and $9 \% \mathrm{w} / \mathrm{v})$. Both strains were found to be resistant to bile salts even after several hours of exposure. Lactobacilli retained their viability as they were recovered on MRS agar after the exposure of the conditions described above

$\mathrm{NaCl}$ (Table 4). The study of hydrophobicity showed that and L. brevis TUCO-7A presented a medium cell surface hydrophobicity while L. curvatus TUCO-5E strain showed a high value in this parameter (Table 4).

Inhibition of bacterial pathogens

As we mentioned previously, the two strains were able to inhibit the growth of E. coli coli TUCO-I6 (EHEC). L. curvatus TUCO-5E showed the most remarkable effect against EHEC. 
We further analyzed whether L. brevis TUCO-7A or L. curvatus TUCO-5E were able to protect intestinal epithelial cells against bacterial pathogens. The exclusion assay showed that $L$. brevis TUCO-7A was able to reduce bacterial cell counts of $S$. enterica ATCC 13096. Interestingly, L. curvatus TUCO-5E significantly reduced counts of pathogenic E. coli and Salmonella (Figure 2). In addition, displacement assays showed no capacity for L. brevis TUCO-7A to reduce intestinal pathogens counts, on the contrary, Salmonella TUCO-I7 and S. enterica ATCC 13096 cells counts were significantly reduced in cells treated with L. curvatus TUCO-5E (Figure 2). Then, considering these results, L. curvatus TUCO-5E was selected for further studies on the protection against Salmonella infection.

In vitro and in vivo anti-Salmonella effect of L. curvatus TUCO-5E

The capacity of L. curvatus TUCO-5E to reduce Salmonella infection was studied in vitro by using electron microscopy (Figure 3). Photographs show the integrity of cell monolayers before pathogen challenge and a significant alteration of monolayer integrity after 45 minutes of Salmonella infection. The epithelium is disrupted and some cell lost the attachment to the wells and developed a round shape. In addition, Salmonella infection induced ruffles and microvilli disruption. On the contrary, in L. curvatus TUCO-5E-tretaed cells, most monolayer conserved the structure and only few round shape cells were observed (Figure 3). Moreover, TUCO-5E-treated cells showed minor surface alterations.

Finally we evaluated in vivo the effect of TUCO-5E strain by using a mice model. L. curvatus TUCO-5E was administered to different groups of mice for 5 consecutive days at doses of $10^{7}, 10^{8}$ or $10^{9}$ cells/mouse/day in the drinking water, and orally challenged with pathogenic Salmonella typhimurium as described previously (Salva et al. 2010). The administration of L. curvatus TUCO$5 \mathrm{E}$ in a dose of $10^{7}$ did not induce significant modifications in the response of mice to Salmonella infection. On the contrary, TUCO-5E administered in doses of $10^{8}$ or $10^{9}$ for 5 days induced a 
311 significant decrease in the number of $S$. typhimurium in the liver and spleen of treated mice when

312 compared to controls (Figure 4). Besides, in the animals that received $10^{9}$ cells of L. curvatus

313 TUCO-5E, the pathogen was not detected in the blood (Figure 4).

314

315

316

317

318

\section{Discussion}

Prerequisites for the healthy and efficient growth of young pigs are the rapid maturation of the gut mucosa and the mucosa-associated lymphoid tissue, and the formation of a local stable and complex bacterial community (Bosi and Trevisi, 2010). Therefore, in the past twenty years, an intensive amount of research has been focused on the development of alternatives to antibiotics to maintain swine health and performance and the most widely researched alternatives include probiotics and prebiotics (Thacker 2013, Villena and Kitazawa 2014, Suda 2015). On the other hand, it was reported that human neonatal gut microbiota establishment represents a crucial stage for gut maturation, metabolic and immunologic programming, and consequently short- and longterm health status. Human milk beneficially influences this process due to its dynamic profile of age-adapted nutrients and bioactive components and by providing commensal maternal bacteria to the neonatal gut. These include Lactobacillus spp., as well as obligate anaerobes such as Bifidobacterium spp., which may originate from the maternal gut via an entero-mammary pathway as a novel form of mother-neonate communication (Bergmann et al. 2014; Jost et al. 2015). Therefore, current research is focusing on human milk bacteria as a source of potential probiotics strains for disease prevention in children. In neonatal pigs, suckling and the maternal environment shape the gut microbiota. Later, when weaning stress causes a transient drop in favorable bacteria, the oral supply of microbes could contribute to re-establish the microbiota balance (Bosi and Trevisi, 2010). Then, similar to human milk, we hypothesized that swine milk could be and excellent source for potential probiotic strains with the capacity to improve protection against bacterial gastrointestinal pathogens in pigs. 
Here, we isolated several LAB strains from swine milk and evaluated their potential as

probiotics. Among the isolated strains, L. curvatus TUCO-5E showed several characteristics that would allow it to be used as a swine probiotic. To remain and exert probiotic potential within their host, several factors are usually considered. Probiotic strains must possess the ability to overcome the extremely low $\mathrm{pH}$ of gastric juice and the detergent effect of bile salts and arrive at the site of action in a viable physiological state (Kim et al. 2007). In vitro experiments demonstrated that $L$. curvatus TUCO-5E posse those characteristics.

In addition, an important requirement of probiotic strains is their safety, as they should not take genes encoding detrimental factors such as haemolysins or genes that confer antibiotic resistance (Kim et al. 2007). We demonstrated that L. curvatus TUCO-5E is a safe strain since no $\alpha$ or $\beta$-haemolytic or gelatinase activities were shown for this strain, and no side effects were observed after its administration to adult mice (data not shown). Notably, the TUCO-5E strain is resistant to vancomycin, supporting the native resistance of several lactobacilli species to vancomycin which is consistent with previous reports (Liu et al. 2009; Temmerman et al. 2002; Danielsen and Wind, 2003, Zhou et al. 2005).

Weaning-associated intestinal inflammation occurs in various animal species including the pig. Intensification of the pig industry has brought increased risks of both clinical and sub-clinical enteric disease. Piglets are vulnerable to potentially harmful microorganisms such as pathogenic $E$. coli, and Salmonella spp. (Williams et al. 2001).

Several studies reported the ability of probiotics to improve resistance against pathogenic $E$. coli. Probiotic LAB are able to reduce ETEC counts in the gut, decrease diarrhea (Qiao et al. 2004; Herfel et al. 2013) and beneficially modulate the inflammatory response against this intestinal pathogen (Li et al. 2012; Shimazu et al. 2012; Villena et al. 2012; Tomosada et al. 2013). Those beneficial effects of probiotics allow an improvement in the growth and health performance of weaning pigs (Li et al. 2012; Suda et al. 2014). We showed here that L. curvatus TUCO-5E significantly inhibit the growth of two pathogenic E. coli strains: TUCO-I5 and TUCO-I6 that are 
363

364

365

366

367

368

369

370

371

372

373

374

375

EHEC and ETEC respectively. Moreover, L. curvatus TUCO-5E was able to significantly reduce EHEC and ETEC bacterial cell counts when evaluated in exclusion assay using an intestinal epithelial cell line. Then, similarly to other probiotic lactobacilli, TUCO-5E would have the potential to induce protection against ETEC and EHEC. In this work, we were not able to develop a mice model to test in vivo the protective effect of L. curvatus UCO-5E against pathogenic E. coli. Those studies are an important point for future near research.

In addition ETEC and EHEC, Salmonella infection is common intestinal pathogen in pigs, especially in the weaning stage (De Busser et al. 2013). Salmonella outbreaks and subclinical infections are often not only the cause of economic and animal welfare costs, but also a source of contamination of pork products entering the food chain since it has long been recognized that swine may be asymptomatic carriers of Salmonella (Funk et al. 2004). Therefore, several studies also focused in the use of probiotic microorganisms to control Salmonella infection in pig and some interesting results have been reported. It was reported that L. zeae- or L. casei-fermented feeds are able to reduce severity of diarrhea in pigs after the challenge with Salmonella and, that those effects were related to improvements in the inflammatory response (Yin et al. 2014). Further, Rieger et al. (2015) showed that E. faecium NCIMB is able to increase intraepithelial lymphocytes numbers in weaned pigs and enhance protection against Salmonella enterica serovar Typhimurium. These studies demonstrate that is possible to modulate pigs' resistance against Salmonella. We showed here that L. curvatus TUCO-5E was capable of reducing the growth of Salmonella and protect intestinal epithelial cells against this bacterial pathogen. Moreover, by using an infection mice model (Salva et al. 2010), we demonstrated that the administration of L. curvatus TUCO-5E induced a significant decrease in S. typhimurium counts in infected organs and blood when compared to controls, demonstrating in vivo the protective effect of TUCO-5E strain. Although it should be tested in the porcine host, these results suggest that L. curvatus TUCO-5E feed supplementation could be used for the prevention of intestinal infections in the pig. In addition, the precise mechanism of action of TUCO-5E strain has to be clarified. 
Reports highlighting the positive effects of probiotics on the performance of pigs or on in

390

391

392

393

394

395

396

397

398

399

400

vitro traits are now quite frequent, but the use of probiotics in feed compounds has not been widespread (Bosi and Trevisi, 2010). Therefore, the search of probiotic strains and the development of functional feeds for the porcine host is still a challenge. In this regard, there is a need for development of alternative control methods to the antibiotics used in feed to protect the animals from gastrointestinal infectious diseases. One of the alternative methods is biological control by probiotics. We demonstrated here that swine milk is an interesting source for finding beneficial bacteria. In addition, the results of this work suggest that L. curvatus UCO-5E is a good candidate for in vivo studying the protective effect of probiotics against intestinal infection and damage induced by Salmonella infection in the porcine host. 


\section{References}

403

404

405

406

407

408

409

410

411

412

413

414

415

416

417

418

419

420

421

422

423

424

425

426

Bergmann H, Rodríguez J.M., Salminen S., Szajewska H. 2014. Probiotics in human milk and probiotic supplementation in infant nutrition: a workshop report. Br. J. Nutr. 112(7):1119-28.

Bosi P, Trevisi P. 2010. New topics and limits related to the use of beneficial microbes in pig feeding review. Benef. Microbes. 1(4):447-54. doi: 10.3920/BM2010.0036.

Cromwell G.L. 2002. Why and how antibiotics are used in swine production. Anim. Biotechnol. 13:7-27.

Danielsen, A.A. Wind. 2003. Susceptibility of Lactobacillus ssp. to antimicrobial agents. Int. J. Food Microbiol. 82 : 1-11.

Emborg H.D., Andersen J.S., Seyfarth A.M., Wegener H.C. 2004. Relations between the consumption of antimicrobial growth promoters and the occurrence of resistance among Enterococcus faecium isolated from broilers. Epidemiol. Infect. 132:95-105.

Funk J., Gebreyes W.A. 2004. Risk factor associated with Salmonella prevalence on swine farms. Journal of Swine Health and Management 12:246-351.

Herfel, T.M., Jacobi, S.K., Lin, X., Jouni, Z.E., Chichlowski, M., Stahl, C.H., and Odle, J. 2013. Dietary supplementation of Bifidobacterium longum strain AH1206 increases its cecal abundance and elevates intestinal interleukin-10 expression in the neonatal piglet. Food Chem. Toxicol. 60, 116-122.

Jost T., Lacroix C., Braegger C., Chassard C. 2015. Impact of human milk bacteria and oligosaccharides on neonatal gut microbiota establishment and gut health. Nutr. Rev. 73(7):426-37.

Kim P.I., Jung M.Y., Chang Y.H., Kim S., Kim S.J., Park Y.H. 2007. Probiotic properties of Lactobacillus and Bifidobacterium strains isolated from porcine gastrointestinal tract. Appl. Microbiol. Biotechnol. 74:1103-1111. 
427

428

429

430

431

432

433

434

435

436

437

438

439

440

441

442

443

444

445

446

447

448

449

450

451

452

Latuga M.S., Stuebe A., Seed P.C. 2014. A review of the source and function of microbiota in breast milk. Semin. Reprod. Med. 32(1):68-73.

Lee, J.S., Awji, E.G., Lee, S.J., Tassew, D.D., Park, Y.B., Park, K.S., Kim, M.K., Kim, B., and Park, S.C. 2012. Effect of Lactobacillus plantarum CJLP243 on the growth performance and cytokine response of weaning pigs challenged with enterotoxigenic Escherichia coli. J. Anim. Sci. 90, 3709-3717.

Li, X.Q., Zhu, Y.H., Zhang, H.F., Yue, Y., Cai, Z.X., Lu, Q.P., Zhang, L., Weng, X.G., Zhang, F.J., Zhou, D., Yang, J.C., and Wang, J.F. 2012. Risks associated with high-dose Lactobacillus rhamnosus in an Escherichia coli model of piglet diarrhoea: intestinal microbiota and immune imbalances. PLoS ONE 7(7): e40666. doi: 10.1371/journal.pone.0040666.

Liu, Z.Y., Zhang, K. Dong, J.P. Yuan, X.K. Guo. 2009. Antibiotic resistance of probiotic strains of lactic acid bacteria isolated from marketed foods and drugs. Biomed. Environ. Sci., 22 (5): $401-412$.

Martín, R., Langa S., Reviriego C., Jimínez E., Marín M.L., Xaus J., Fernández L., Rodríguez J.M. 2003. Human milk is a source of lactic acid bacteria for the infant gut. J. Pediatr., 143: 754758.

Qiao, S., Huang, C., Lifa, D., Piao, X., and Ren, J. 2004. Effects of lactobacilli on the performance, diarrhea incidence, VFA concentration and gastrointestinal microbial flora of 29 weaning pigs. Asian-Australasian J. Ani. Sci. 17, 401-409.

Rieger J., Janczyk P., Hünigen H., Neumann K., Plendl J. 2015. Intraepithelial lymphocyte numbers and histomorphological parameters in the porcine gut after Enterococcus faecium NCIMB 10415 feeding in a Salmonella Typhimurium challenge. Vet. Immunol. Immunopathol. 164(12):40-50.

Salva S., Villena J., Alvarez S. 2010. Immunomodulatory activity of Lactobacillus rhamnosus strains isolated from goat milk: impact on intestinal and respiratory infections. Int. J. Food Microbiol. 141(1-2):82-9. 
453

454

455

456

457

458

459

460

461

462

463

464

465

Shimazu T., Villena J., Tohno M., Fujie H., Hosoya S., Shimosato T., Aso H., Suda Y., Kawai Y., Saito T., Makino S., Ikegami S., Itoh H., Kitazawa H. 2012. Immuno-biotic Lactobacillus jensenii elicit anti-inflammatory activity in porcine intestinal epithelial cells by modulating negative regulators of the toll-like receptor signaling pathway. Infect. Immun. 80:276-88.

Suda Y., Villena J, Takahashi Y., Hosoya S., Tomosada Y., Tsukida K., Shimazu T., Aso H., Tohno M., Ishida M., Makino S., Ikegami S., and H. Kitazawa. 2014. Immunobiotic Lactobacillus jensenii as immune-health promoting factor to improve growth performance and productivity in post-weaning pigs. BMC Immunol. 14:24.

Temmerman, B. Pot, G. Huys, J. Swings. 2002. Identification and antibiotic susceptibility of bacterial isolates from probiotic products. Int. J. Food Microbiol. 81:1-10.

Thacker, P. A. 2013. Alternatives to antibiotics as growth promoters for use in swine production: a review. Anim. Sci. Biotechnol. 4(1), 35. http://doi.org/10.1186/2049-1891-4-35

Tomosada Y., Villena J., Murata K., Chiba E., Shimazu T., Aso H., Iwabuchi N., Xiao J., Saito T., Kitazawa H. 2013. Immunoregulatory effect of Bifidobacteria strains in porcine intestinal epithelial cells through modulation of ubiquitin-editing enzyme A20 expression. PLoS One. 8(3):e59259. doi: 10.1371/journal.pone.0059259.

Villena J. and Kitazawa H. 2014. Modulation of intestinal TLR4-inflammatory signalling pathways by probiotic microorganisms: lessons learned from Lactobacillus jensenii TL2937. Special issue: Toll-Like Receptor Activation in Immunity vs. Tolerance. Frontiers in Immunology (Frontiers in Immunological Tolerance) 4(512):1-12.

Villena J., Suzuki R., Fujie H., Chiba E., Takahashi T., Tomosada Y., Shimazu T., Aso H., Ikegami S., Itoh H., Alvarez S., Saito T., Kitazawa H. 2012. Immunobiotic Lactobacillus jensenii modulates toll-like receptor 4-induced inflammatory response via negative regulation in porcine antigen presenting cells. Clin. Vaccine. Immunol.19:1038-53.

Williams, B.A., Verstegen, M.W.A., and Tamminga, S. 2001. Fermentation in the large intestine of single-stomached animals and its relationship to animal health. Nut. Res. Rev. 14, 207-227. 
479 Yin F., Farzan A., Wang Q.C., Yu H., Yin Y., Hou Y., Friendship R., Gong J. 2014. Reduction of 480 Salmonella enterica serovar Typhimurium DT104 infection in experimentally challenged 481 weaned pigs fed a Lactobacillus-fermented feed. Foodborne Pathog. Dis. 11(8):628-34.

482 Zhou J.S., C.J. Pillidge, P.K. Gopal, H.S. Gill. 2005. Antibiotic susceptibility profiles of new 483 probiotic Lactobacillus and Bifidobacterium strains. Int. J. Food Microbiol., 98 : 211-217.

484 
Figure legends

487

Figure 1. Characterization of Lactobacillus strain. A) Lactobacillus brevis TUCO-7A strain is pearl like colony in MRS agar. Photos represent data from three independent experiments.

492

493

Figure 4. In vivo protective effect of Lactobacillus curvatus TUCO-5E. L. curvatus TUCO$5 \mathrm{E}$ was administered to different groups of mice for 5 consecutive days at dose of $10^{7}, 10^{8}$ or $10^{9}$ cells/mouse/day in the drinking water. Treated and control mice were challenged with $10^{7}$ cells/mouse of S. typhimurium (20LD50) by oral administration. Mice were sacrificed on days 2 post-infection. Liver, spleen and blood samples were taken for bacterial cell counts. The results represent data from three independent experiments. Asterisks indicate significant differences * $(\mathrm{P}<0.05), * *(\mathrm{P}<0.01)$. 
Lactobacillus brevis UCO-7A
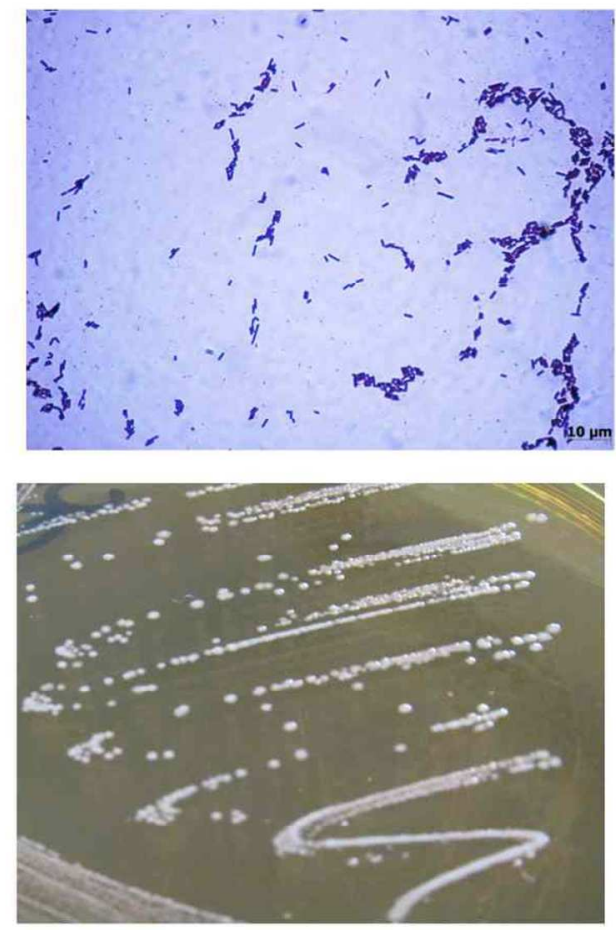

Lactobacillus curvatus UCO-5E
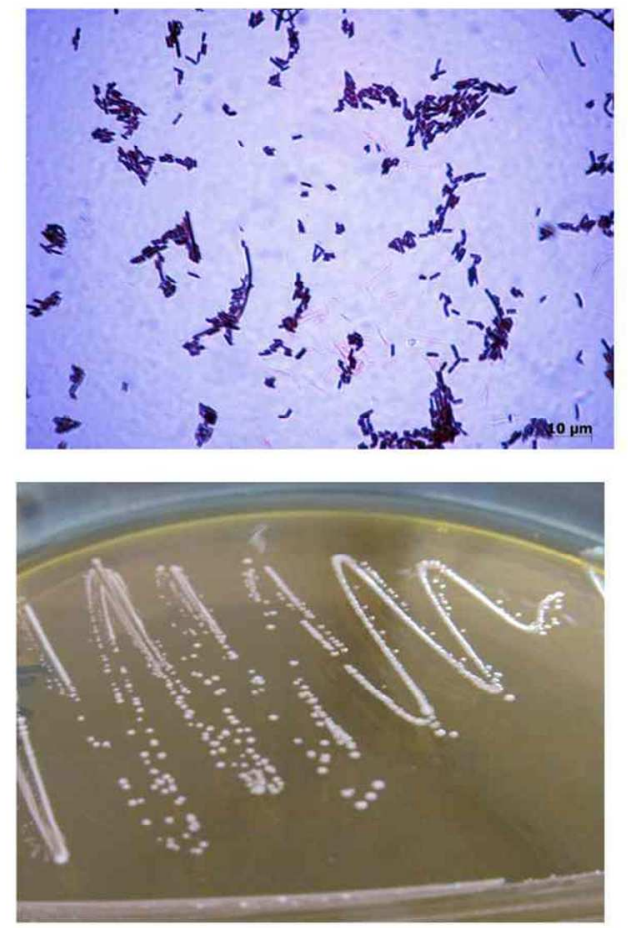

$213 \times 177 \mathrm{~mm}(150 \times 150 \mathrm{DPI})$ 


\section{Exclusion assay}

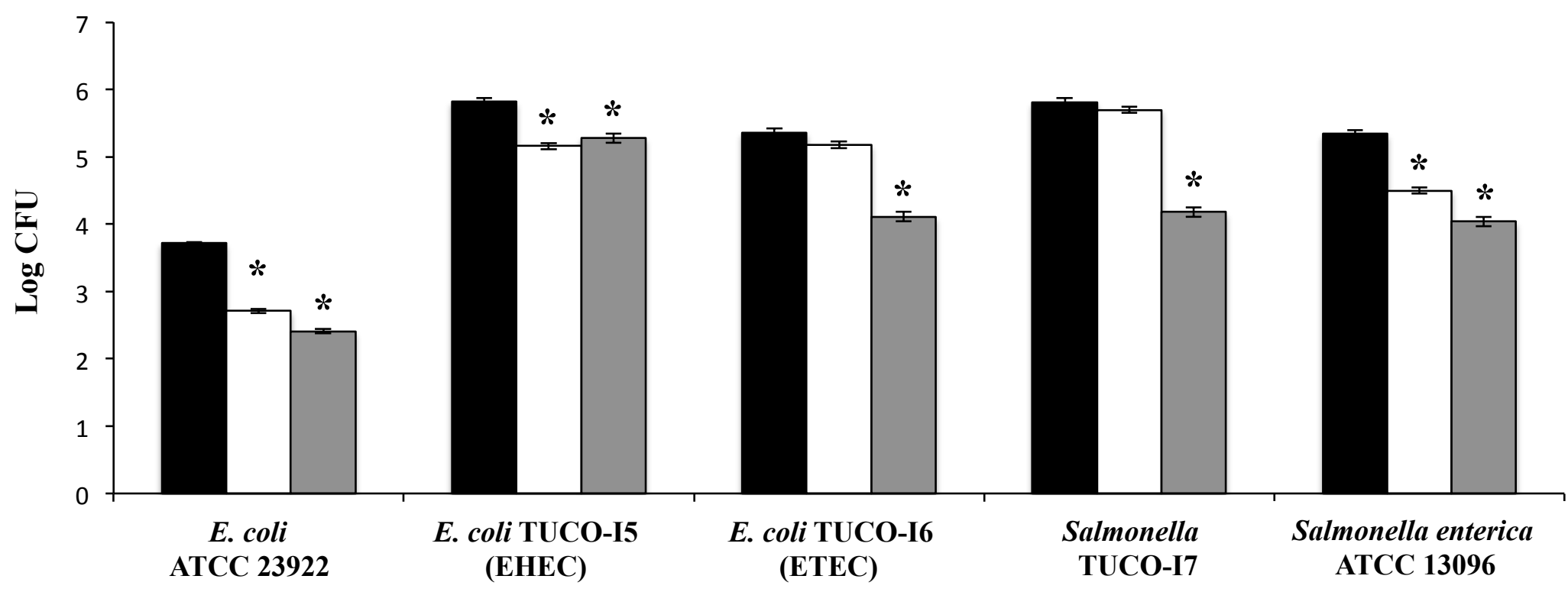

\section{Displacement assay}



https://mc06.manuscriptcentral.com/cjm-pubs

$\square$ Control $\square$ L. brevis TUCO-7A $\square$ L. curvatus TUCO-5E 


\section{Uninfected control cells}

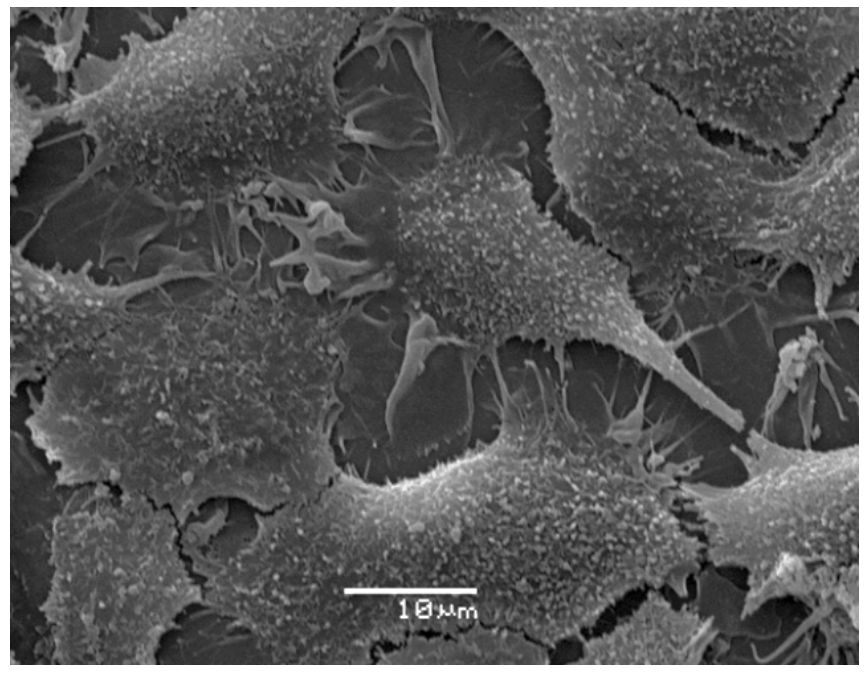

Salmonella infected cells

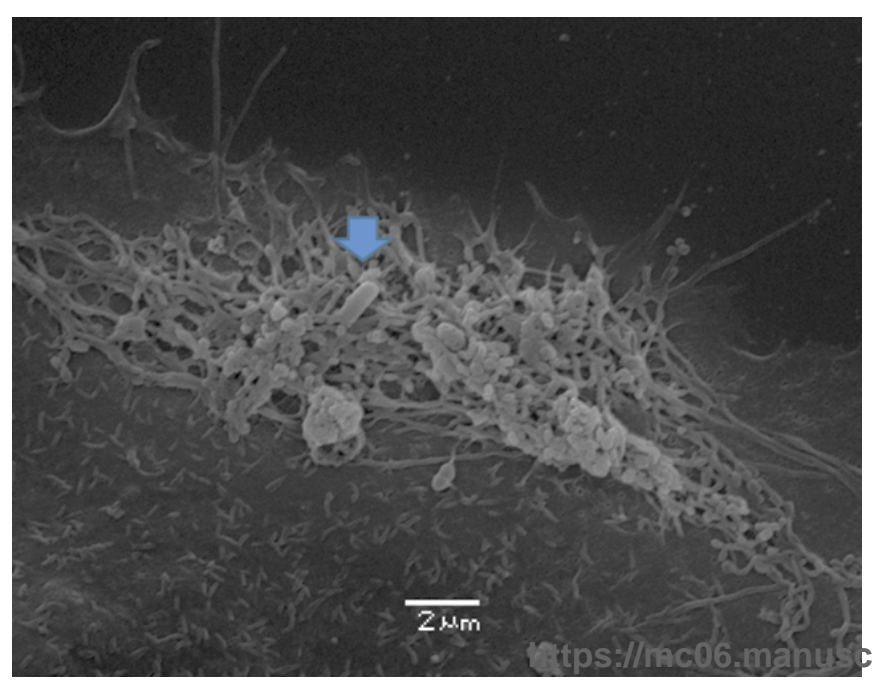

Salmonella infected cells

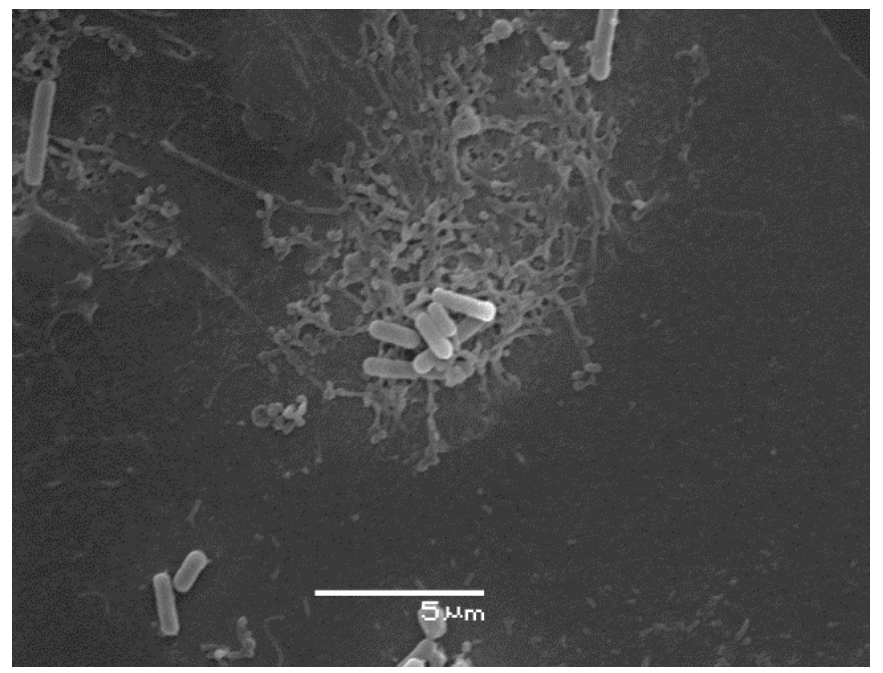

\section{L. curvatus TUCO-5E + Salmonella}

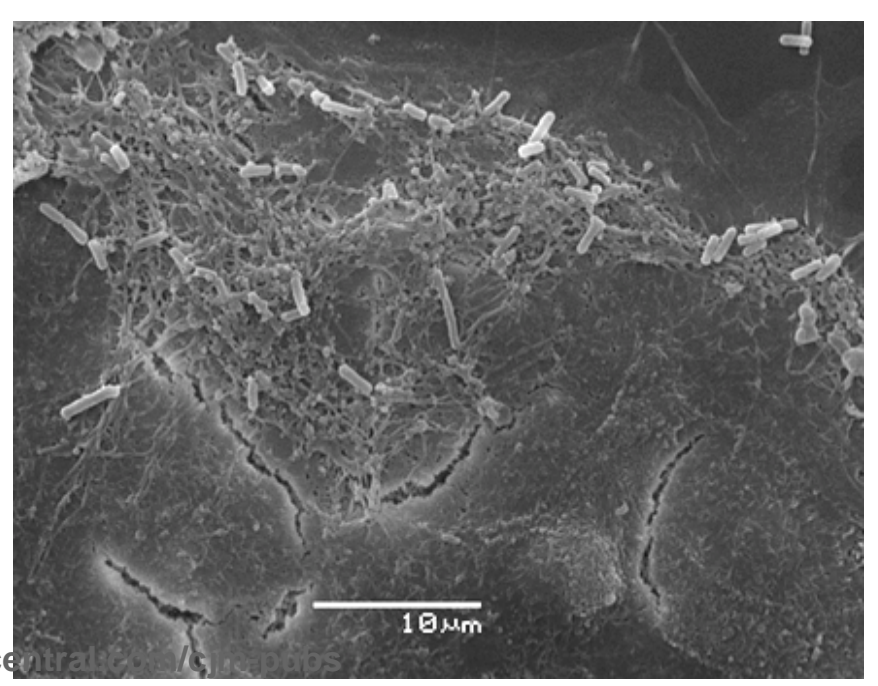


$10^{7}$ cells

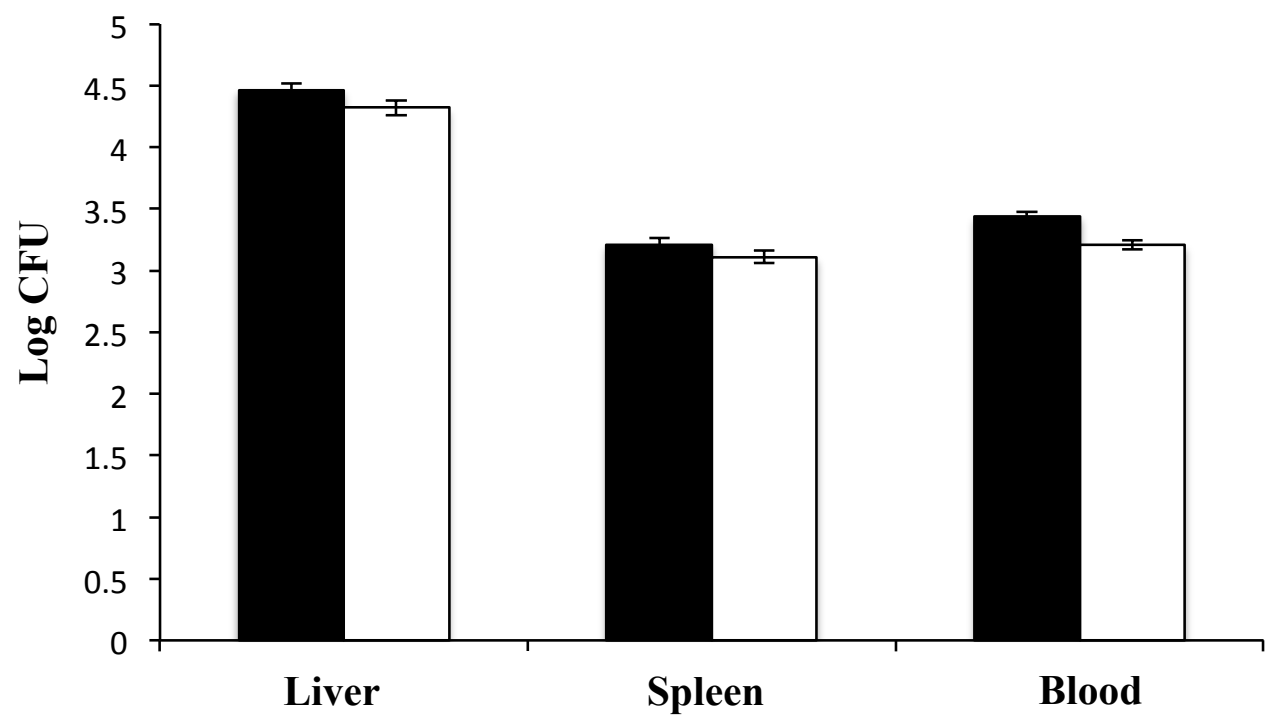

$10^{8}$ cells

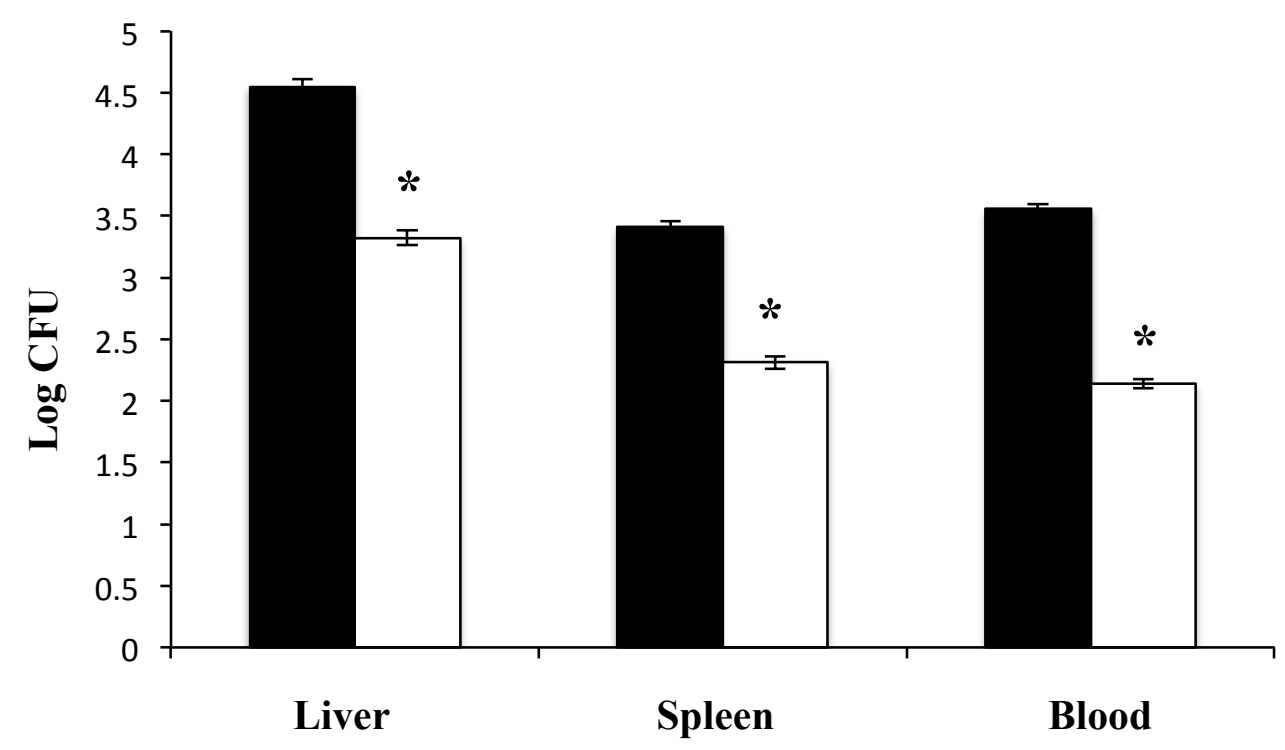

$10^{9}$ cells

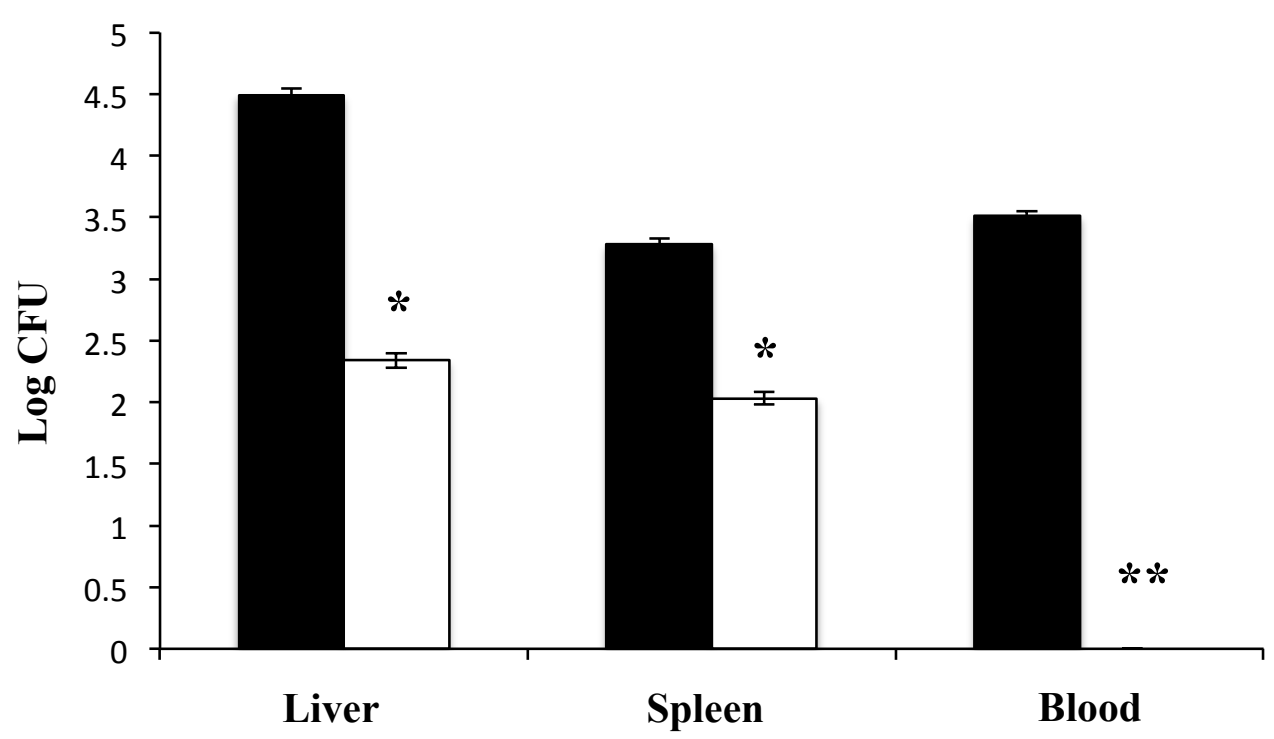


Table 1. Primers used for the identification of lactobacillus species.

\begin{tabular}{|c|c|c|}
\hline Lactobacillus spp. & Primers & Sequences \\
\hline \multirow{2}{*}{ L. acidophilus } & Aci 16SI & 5' AGC TGA ACC AAC AGA TTC AC \\
\hline & $16 \mathrm{SII}$ & $5^{\prime}$ ACT ACC AGG GTA TCT AAT CC \\
\hline \multirow{2}{*}{ L. crispatus } & Cri 16SI & 5'GTA ATG ACG TTA GGA AAG CG \\
\hline & Cri16SII & 5'ACT ACC AGG GTA TCT AAT CC \\
\hline \multirow{2}{*}{ L. gasseri } & Gas I & 5'GAG TGC GAG AGC ACT AAA G \\
\hline & Gas II & 5'CTA TTT CAA GTT GAG TTT CTC T \\
\hline \multirow{2}{*}{ L. johnsonii } & Joh 16SI & 5'GAG CTT GCC TAG ATG ATT TTA \\
\hline & Joh 16SII & 5'ACT ACC AGG GTA TCT AAT CC \\
\hline \multirow{2}{*}{ L. plantarum } & Lfpr & 5'GCC GCC TAA GGT GGG ACA GAT \\
\hline & PlanII & 5'TTA CCT AAC GGT AAA TGC GA \\
\hline \multirow{2}{*}{ L. casei } & PrI & 5'CAG ACT GAA AGT CTG ACG G \\
\hline & CasII & 5'GCG ATG CGA ATT TCT TTT TC \\
\hline \multirow{2}{*}{ L. zeae } & ZeaI & 5'TGT TTA GTT TTG AGG GGA CG \\
\hline & ZeaII & ATG CGA TGC GAA TTT CTA AAT T \\
\hline \multirow{2}{*}{ L. rhamnosus } & PrI & 5'CAG ACT GAA AGT CTG ACG G \\
\hline & RhaII & 5'GCG ATG CGA ATT TCT ATT ATT \\
\hline \multirow{2}{*}{ L. reuteri } & Lfpr & 5'GCC GCC TAA GGT GGG ACA GAT \\
\hline & Reu & 5'AAC ACT CAA GGA TTG TCT GA \\
\hline \multirow{2}{*}{ L. fermentum } & Lfpr & 5'GCC GCC TAA GGT GGG ACA GAT \\
\hline & Fermi & 5'CTG ATC GTA GAT CAG TCA AG \\
\hline \multirow{2}{*}{ L. sharpeae } & ShaI & 5'GAT AAT CAT GTA AGA AAC CGC \\
\hline & ShaII & 5’ATA TTG TTG GTC GCG ATT CG \\
\hline \multirow{2}{*}{ L. salivarius } & Lsal I & 5'ATT CGC TAA ACT CAT AAC CT \\
\hline & Lsal II & 5'CAC TCT CTT TGG CTA ATC TT \\
\hline
\end{tabular}


Table 2. Antibiotic resistance of lactic acid bacteria from swine milk

\begin{tabular}{cccc}
\hline Antibiotic & Concentration & brevis TUCO-7A & curvatus TUCO-5E \\
\hline Ciprofloxacin & $5 \mu \mathrm{g}$ & Resistant & Susceptible \\
Vancomicin & $30 \mu \mathrm{g}$ & Resistant & Resistant \\
Amoxicillin & $25 \mu \mathrm{g}$ & Susceptible & Susceptible \\
Ampicillin & $10 \mu \mathrm{g}$ & Susceptible & Susceptible \\
Gentamicin & $10 \mu \mathrm{g}$ & Susceptible & Susceptible \\
Erythromycin & $15 \mu \mathrm{g}$ & Susceptible & Susceptible \\
Doxycycline & $30 \mu \mathrm{g}$ & Intermediate & Resistant \\
\hline
\end{tabular}


Table 3. Hemolysins and gelatinases detection in lactic acid bacteria from swine milk

\begin{tabular}{ccc}
\hline & Lactobacillus & Lactobacillus \\
& brevis TUCO-7A & curvatus TUCO-5E \\
\hline$\alpha$-haemolysis & Negative & Negative \\
$\beta$-haemolysis & Negative & Negative \\
gelatinase activity & Negative & Negative \\
\hline
\end{tabular}


Table 4. Cell surface hydrophobicity and resistance to gastrointestinal conditions of lactic acid bacteria from swine milk

\begin{tabular}{|c|c|c|}
\hline & Lactobacillus brevis & Lactobacillus curvatus \\
\hline & TUCO-7A & TUCO-5E \\
\hline \multicolumn{3}{|l|}{$\mathrm{NaCl}(\%)$} \\
\hline 3.0 & +++ & ++++ \\
\hline 6.5 & ++ & + \\
\hline 9.0 & + & + \\
\hline \multicolumn{3}{|l|}{ Oxgall (\%) } \\
\hline 0.3 & +++ & ++++ \\
\hline 0.6 & +++ & +++ \\
\hline 2.0 & +++ & +++ \\
\hline 3.0 & +++ & +++ \\
\hline 5.0 & +++ & +++ \\
\hline Hydrophobicity (\%) & 47.4 (medium) & 87.2 (high) \\
\hline
\end{tabular}

Low growth: +, Medium growth: ++, High growth: +++

Low: $0-35 \%$, Medium: $36-70 \%$, High: $71-100$. 
Table 5. Inhibition of bacterial pathogens by lactic acid bacteria from swine milk

\begin{tabular}{|c|c|c|c|c|c|}
\hline Strain & E. coli ATCC 23922 & E. coli TUCO-I5 (EHEC) & E. coli TUCO-I6 (ETEC) & Salmonella TUCO-I7 & S. enterica ATCC 13096 \\
\hline \multicolumn{6}{|l|}{ Lactobacillus } \\
\hline brevis TUCO-7A & $2.00 \pm 0.23$ & $1.53 \pm 0.36$ & $1.98 \pm 0.19$ & $2.23 \pm 0.39$ & $2.38 \pm 0.21$ \\
\hline \multicolumn{6}{|l|}{ Lactobacillus } \\
\hline curvatus TUCO-5E & $1.98 \pm 0.33$ & $1.78 \pm 0.28$ & $1.93 \pm 0.30$ & $2.88 \pm 0.10$ & $3.03 \pm 0.22$ \\
\hline
\end{tabular}

